\title{
STRATEGI KOMUNIKASI \\ PENERIMAAN MAHASISWA BARU \\ DI UNIVERSITAS MUHAMMADIYAH CIREBON
}

\section{Teddy Dyatmika}

Dosen Universitas Muhammadiyah Cirebon

Email:tedyrnt@gmail.com

\begin{abstract}
ABSTRAK
Universitas Muhammadiyah Cirebon (UMC) adalah perguruan tinggi yang sedang berkembang di wilayah III Cirebon (Cirebon Kota/Kab, Majalengka, Indramayu dan Kuningan) saat ini. Mengantongi akretidasi "B" seharusnya menjadi daya tarik bagi para calon mahasiswa baru untuk bergabung dengan kampus utama yang terletak di Jl. Watubelah-Sumber Cirebon ini. Apalagi Universitas Muhammadiyah Cirebon memiliki beberapa keunggulan dibandingkan perguruan tinggi lain. Lokasi kampus yang Strategis, biaya perkuliahan yang relatif terjangkau, menjadi nilai tambah bagi para calon mahasiswa baru untuk menentukan pilihannya menuntut ilmu di Universitas Muhammadiyah Cirebon. Namun, fakta di lapangan tidak semua fresh graduate melirik UMC sebagai universitas alternatif untuk mereka kuliah.
\end{abstract}

Kata Kunci: Mahasiswa, Promosi, Strategi Komunikasi

\section{ABSTRACT}

Muhammadiyah University of Cirebon (UMC) is a university that is currently developing in the region III Cirebon (Cirebon Kota / Kab, Majalengka, Indramayu and Kuningan) today. Bagging " $B$ " accretion should be an attraction for prospective new students to join the main campus located on Jl. These Cirebon Sources. Moreover, Cirebon Muhammadiyah University has several advantages over other universities. Strategic campus location, relatively affordable tuition fees, is an added value for prospective new students to determine their choice to study at Muhammadiyah University in Cirebon. However, in fact, not all fresh graduates look at UMC as an alternative university for them to study.

Keyword: Students, Promotion, Communication Strategy 


\section{PENDAHULUAN}

Universitas

Muhammadiyah

Cirebon (UMC) resmi berdiri pada bulan September tahun 2000. Visi dari UMC adalah "Menjadi Universitas Unggulan yang Islami, Profesional dan Mandiri”. Sedangkan Misi dari UMC adalah: (1) Menyelenggarakan kegiatan Catur Dharma Perguruan Tinggi Muhammadiyah secara terpadu, (2) Menciptakan suasana akademik yang mendukung pada peningkatan kualitas sesuai dengan Standar Nasional Pendidikan Tinggi,

Menyelenggarakan kegiatan penelitian dan pengabdian kepada masyarakat yang mendorong perkembangan IPTEK dan dapat memenuhi kebutuhan dunia usaha dan industri, (4) Mendorong sikap kewirausahaan.

Awal berdirinya UMC memiliki 3 Fakultas yaitu: Fakultas Ekonomi, Fakultas Teknik dan Fakultas Ilmu Sosial dan Ilmu Politik dan memiliki 9 program studi serta satu buah gedung sebagai sarana perkuliahan yang berada di Jalan Tuparev nomor 70, Kabupaten Cirebon. Pada tahun 2009 berdiri 2 Fakultas baru yaitu Fakultas Keguruan dan Ilmu Pendidikan dan Fakultas Ilmu Kesehatan.

Pada tahun 2015 lahirlah satu Fakultas baru yaitu Fakultas Hukum dengan program studi Ilmu Hukum. Sehingga pada tahun 2015 UMC sudah memiliki 6 Fakultas dan 19 program studi. Pada tahun 2017 lahirlah satu Fakultas baru yaitu Fakultas Agama Islam dengan 2 Program Studi yaitu Ilmu AlQuran Tafsir dan Tasawuf Psikoterapi. Sehingga saat ini UMC sudah memiliki 7 Fakultas dan 21 Program Studi. Dari segi fasilitas UMC memiliki 5 kampus yang tersebar di Kabupaten Cirebon.

Pada tahun 2017 UMC menerimara mahasiswa baru sebanyak 1373 mahasiswa sedangkan pada tahun 2018 jumlah mahasiswa baru UMC mencapai 1622. Meskipun terjadi peningkatan, tetapi jumlah peningkatannya tidak signifikan apalagi ada penambahan 2 program studi baru dari tahun 2017 ke tahun 2018. Selain itu ada perubahan akreditasi dari 6 program studi yang awalnya terakreditasi "C" berubah menjadi akreditasi "B". Status akreditasi perguruan tinggi pun mengalami perubahan dari yang awalnya " $\mathrm{C}$ " berubah menjadi terakreditasi "B". Dari fenomena inilah peneliti ingin mengetahui strategi yang digunakan oleh UMC untuk menarik perhatian mahasiswa agar mau bergabung dan kuliah di UMC. 
Menurut Morissan (2010:5) sebuah pemasaran memfasilitasi proses dimana pertukaran dan peningkatan hubungan dengan konsumen dengan cara mencermati dengan baik kebutuhan dan keinginan dari konsumen yang dilanjutkan dengan mengembangkan produk (product) yang dapat memberikan kepuasan kepada konsumennya. Kemudian produk tersebut ditawarkan dengan harga (price) tertentu kepada konsumen. Setelah itu harus didistribusikan di tempat (place) yang potensial untuk diterimanya produk tersebut.

Dalam proses tersebut juga sangat diperlukan yang namanya promosi (promotion). Begitu juga dengan penerimaan mahasiswa baru (PMB) UMC. Produk yang ditawarkan oleh UMC adalah bidang pendidikan dengan bermodalkan Sumber Daya Manusia, Fasilitas yang memadahi, Akreditasi Perguruan Tinggi dan Program Studi dan lain sebagainya. Sedangkan dalam bentuk tempatnya adalah lingkungan strategis kampus yang terdiri dari 5 kampus yang mudah terjangkau oleh berbagai angkutan baik umum maupun pribadi.

Dari segi harganya, kuliah di UMC harganya lebih kompetitif dibandingkan dengan kampus swasta lainnya disekitar wilayah Cirebon, Majelengka, Indramayu dan Kuningan. Sedangkan dari segi promotion dalam hal ini adalah segala sesuatu yang dilakukan oleh tim PMB UMC dalam mempromosikan UMC kepada masyarakat luas tidak hanya di lingkup wilayah Cirebon, Majelengka, Indramayu dan Kuningan, kalau bisa diseluruh wilayah Indonesia bahkan di tingkat International.

Menurut Cangara (2013:80) dari keempat elemen tersebut, suatu produk yang ingin dipasarkan memerlukan promosi. Sedangkan promosi memerlukan strategi dalam perencanaan komunikasi. Anggapan seseorang bahwa dalam melakukan promosi sangat membutuhkan biaya yang relatif tinggi, padahal biaya yang dikeluarkan untuk promosi harus dinilai sebagai investasi.

Proses bauran pemasaran saja sekarang ini tidaklah cukup. Kita perlu mengintegrasikan proses pemasaran dalam hal ini PMB UMC menggunakan Komunikasi Pemasaran Terpadu (Intregrated Marketing Communication). Menurut Shimp (2003:24) Intregrated Marketing Communication adalah sebuah proses peningkatan, pengembangan dan implementasi berbagai bentuk program komunikasi persuasif kepada pelanggan dan calon pelanggan secara 
berkelanjutan. Proses Intregrated

Marketing Communication berawal dari pelanggan atau calon pelanggan lalu berbalik kepada sebuah organisasi atau perusahaan dalam menentukan dan mendefinisikan bentuk dan metode yang perlu dilakukan pengembangan bagi program komunikasi persuasif.

Intinya adalah ciri utama dari Intregrated Marketing Communication:

(1) mempengaruhi perilaku konsumen atau pelanggan; (2) berawal dari pelanggan dan calon pelanggan; (3) melakukan satu atau segala cara dalam melakukan kontak dengan pelanggan atau calon pelanggan; (4) berusaha menciptakan sebuah sinergi; (5) menjalin hubungan yang baik antara organisasi atau perusahaan dengan pelanggannya.

\section{METODOLOGI PENELITIAN}

Paradigma yang digunakan dalam penelitian ini adalah menggunakan paradigma kualitatif. Dimana peneliti mencari kedalaman data dalam proses penelitian. Seperti yang disampaikan oleh Kriyantono (2014:56-57) yang menyatakan bahwa riset kualitatif memiliki tujuan bagaimana menjelaskan sebuah fenomena dengan sedalam dalamnya melalui pengumpulan data.
Dalam sebuah penelitian kualitatif inilah peneliti tidak perlu mencari data sebanyak banyaknya. Data tersebut sudah dikatakan cukup apabila informan sudah memberikan secara lengkap data yang telah dibutuhkan. Jadi penekanan pada penelitian ini adalah pada kedalaman data yang diperoleh bukan banyaknya data yang dikumpulkan.

Dalam melakukan penelitian kualitatif keterlibatan adalah upaya penting misalnya mengajukan pertanyaan, melakukan pengumpulan data yang spesifik, melakukan analisis data secara induktif dari tema khusus ke tema umum, dan melakukan penafsiran dari makna data tersebut (Cresswell, 2010:5).

Pada penelitian ini peneliti menggunakan purposive sampling. Teknik pengambilan sampling ini masuk dalam teknik pengambilan sample non probabilitas dimana sampel diambil tidak melalui pengambilan acak. Teknik pengambilan sampel menggunakan teknik purposive sampel yaitu teknik pengambilan sampel dimana orang-orang diseleksi atas dasar kriteria-kriteria tertentu yang dibuat periset berdasarkan tujuan riset. Sedangkan orang yang berada dalam populasi yang tidak sesuai 
dengan kriteria tidak dijadikan sampel (Kriyantono, 2014:158).

Menurut Arikunto

penelitian agar hasilnya berkualitas maka data yang terkumpul haruslah lengkap baik itu data primer maupun skunder. Data primer yaitu data yang peneliti peroleh langsung dari informan dalam hal ini adalah ketua PMB dan mahasiswa. Sedangkan data sekunder adalah data yang diperoleh tidak secara langsung dari objek penelitian salahsatunya jumlah mahasiswa baru.

Pada penelitian ini yang dijadikan informan adalah Ketua Penerimaan Mahasiswa Baru yaitu Bapak M. Kamaluddin, M.Hum dan dari beberapa mahasiswa yang berasal dari 21 program studi. Pada penelitian ini proses analisis data menggunakan tipe deskriptif. Dimana pada penelitian ini peneliti mendeskripsikan secara sistematis, faktual dan akurat berkaitan dengan data sesungguhnya dilapangan yang peneliti peroleh dari informan (Kriyantono, 2014:69).

Teknik pengumpulan data pada penelitian ini dengan menggunakan wawancara mendalam kepada Ketua Penerimaan Mahasiswa Baru yaitu Bapak M. Kamaluddin, M.Hum dan dari beberapa mahasiswa yang berasal dari 21 program studi. Selanjutnya data yang berasal dari informan dianalisis untuk memperoleh hasil kesimpulannya.

\section{HASIL PENELITIAN}

Masyarakat di Indonesia hampir sebagian besar pernah mendengar nama organisasi Islam "Muhammadiyah". Organisasi Islam yang berdiri di tahun 1912 ini fokus pada 3 bidang yaitu kesehatan, pendidikan dan santunan kepada dhuafa. Dalam bidang pendidikan sendiri organisasi Islam Muhammadiyah memiliki banyak penyelenggara pendidikan mulai dari tingkat PAUD sekitar 17 ribu an lebih PAUD tersebar di seluruh Indonesia, tingkat Sekolah Dasar ada hampir 2.500 lebih, tingkat Sekolah Menengah Pertama ada hampir 1.600 lebih, Sekolah Menengah Atas, Kejuruan dan MA ada sekitar 1.200 lebih. Sedangkan di tingkat Perguruan Tinggi saat ini Organisasi Muhammadiyah memliki kurang lebih 179 Perguruan Tinggi yang ada di seluruh wilayah Indonesia.

Dengan banyaknya satuan pendidikan Muhammadiyah di seluruh Indonesia secara pengetahuan masyarakat pastinya sudah paham betul tentang Perguruan Tinggi Muhammadiyah dengan berbagai reputasi baiknya. Tentu 
ini menjadi nilai tambah yang baik untuk PMB UMC dalam memperoleh mahasiswa baru dalam kuantitas maupun kualitas yang lebih baik setiap tahunnya. Pengetahuan tentang merek dalam hal ini adalah UMC sebagai bagian dari Perguruan Tinggi Muhammadiyah (PTM) dibagi menjadi 2 yaitu brand awareness (kesadaran merek) dan brand image (citra merek).

Menurut Shimp (2003:11) kesadaran merek adalah kemampuan sebuah merek untuk muncul dalam benak konsumen ketika mereka sedang memikirkan kategori produk tertentu dan seberapa mudahnya nama tersebut dimunculkan. Dengan nama besar Muhammadiyah kesadaran merek akan UMC sudah sangat bagus. Ini sudah menjadi pion positif UMC dalam melakukan pengambangan baik dari segi kualitas dan kuantitas dalm proses PMB.
Nama Muhammadiyah yang sudah sangat fmiliar di telinga masyarakat pada umumnya dan masyarakat wilayah Cirebon pada umumnya menjadikan promosi PMB UMC akan lebih mudah dilakukan. Sedangkan yang kedua adalah citra merek, dimana citra merek dapat dianggap sebagai jenis asosiasi yang muncul dibenak konsumen ketika mengingat sebuah merek tertentu. Asosiasi tersebut secara sederhana muncul dalam bentuk pemikiran atau citra tertentu yang dikaitkan kepada suatu merek (Shimp, 2003:12). Citra positif dari Muhammadiyah tentu menjadi nilai tambah bagi UMC. Dimana lulusan dari PTM yang ada di Indonesia saat ini sudah mulai diakui oleh perusahaan-perusahaan besar. Selain itu akreditasi perguruan tinggi dan program studi yang baik juga menjadi nilai tambah sebagia upaya meningkatkan PMB di lingkungan UMC.

Berdasarakan hasil penelusuran dengan tim PMB UMC diperoleh hasil data penerimaan mahasiswa baru di lingkungan UMC pada dua tahun terakhir yaitu tahun 2017/2018 dan 2018/2019 adalah sebagai berikut:

Tabel 1

Jumlah Mahasiswa PMB

(Sumber : Panitia PMB) 


\begin{tabular}{|c|l|c|c|}
\hline \multirow{2}{*}{ No } & \multicolumn{1}{|c|}{ Program Studi } & \multicolumn{2}{|c|}{ Tahun } \\
\cline { 3 - 4 } & & $\mathbf{2 0 1 7 / 2 0 1 8}$ & $\mathbf{2 0 1 8 / 2 0 1 9}$ \\
\hline 1 & Akuntansi & 112 & 119 \\
\hline 2 & Ilmu Hukum & 31 & 46 \\
\hline 3 & Keperawatan & 120 & 152 \\
\hline 4 & Ilmu Komunikasi dan D3 Humas & 101 & 130 \\
\hline 5 & Ilmu Pemerintahan & 137 & 111 \\
\hline 6 & Manajemen & 147 & 188 \\
\hline 7 & Pendidikan Bahasa Inggris & 32 & 50 \\
\hline 8 & Pendidikan IPA & 15 & 12 \\
\hline 9 & Pendidikan Kimia & 11 & 24 \\
\hline 10 & Pendidikan Matematika & 17 & 47 \\
\hline 11 & Peternakan & 11 & 15 \\
\hline 12 & PG PAUD & 93 & 90 \\
\hline 13 & PGSD & 318 & 282 \\
\hline 14 & Profesi Ners & 16 & 14 \\
\hline 15 & Teknik Industri & 68 & 70 \\
\hline 16 & Teknik Informatika & 144 & 156 \\
\hline 17 & Teknik Industri (D3) & 0 & 0 \\
\hline 18 & Teknik Informatika (D3) & 0 & 0 \\
\hline 19 & Ilmu AlQuran dan Tafsir & - & 41 \\
\hline 20 & Tasawuf dan Psikoterapi & $\mathbf{1 3 7 3}$ & $\mathbf{1 6 2 2}$ \\
\hline \multicolumn{2}{|r|}{ Total } & & \\
\hline
\end{tabular}

Dari tabel 1 di atas dapat dilihat bahwa perubahan tidak terjadi signifikan dalam hal kuantitas PMB UMC. Padahal target dalam PMB tahun 2018/2019 adalah bertambahnya jumlah mahasiswa baru secara signifikan dalan hal kuantitas.

Akan tetapi yang terjadi adalah penambahan mahasiswa baru kurang signifikan. Pada tahun 2017/2018 jumlah total mahasiswa 1373 hanya bertambah menjadi 1622 dengan margin 249 mahasiswa saja. Kalau dikurangkan dengan dua program studi baru yang tidak di buka di tahun 2017/2018 maka margin penerimaan mahasiswa baru dari tahun 2017/2018 ke tahun 2018/2019 hanya 133 mahasiswa saja. Ini jelas sangat tidak sesuai target yang telah ditentukan.

Secara akreditasi seharusnya jumlah penerimaan mahasiswa baru mengalami peningkatan. Dari perkembangan perguruan tinggi muhammadiyah di Indonesia, pada saat status akreditasi perguruan tinggi atau program studi mengalami peningkatan maka secara bersamaan jumlah kuantitas pendaftar dan mahasiswa baru di perguruan tinggi tersebut juga mengalami 
peningkatan. Seperti halnya Universitas

Muhammadiyah Surakarta, Universitas

Muhammadiyah Yogyakarta, Universitas

Muhammadiyah Malang dan lainnya.

Pada saat status akreditasi meningkat baik pada tingkat Perguruan Tinggi maupun Program Studi maka secara bersamaan pula jumlah pendaftar mahasiswa baru juga mengalami peningkatan yang cukup signifikan. Tetapi hal tersebut tidak terjadi di UMC. Pada Tahun 2017/2018 akreditasi Perguruan Tinggi UMC terakreditasi " $\mathrm{C}$ " sedangkan pada tahun 2018/2019 akreditasi Perguruan Tinggi UMC terakreditasi "B". Pada tahun 2017/2018 enam (6) program studi di UMC yaitu Ilmu Keperawatan, Profesi Ners, D3 Hubungan Masyarakat, Teknik Industri, Teknik Informatika dan Peternakan status akreditasinya "C" saat ini keenam program studi tersebut sudah terakreditasi "B". Tapi kita lihat tabel 1 di atas menunjukan perubahan tidak terjadi secara signifikan di keenam program studi tersebut. Malah bahkan ada yang mengalami penurunan yaitu di program studi ners.
Dari fenomena di atas ternyata bersumber dari cara promotion yang belum dimanfaatkan secara maksimal. Berdasarkan hasil wawancara yang peneliti lakukan dengan Ketua Penerimaan Mahasiswa Baru promosi yang dilakukan oleh Tim PMB masih pada ranah menggunakan kunjungan ke sekolah-sekolah, media cetak dalam hal ini brosur, leaflet media elektronik melalui radio terintegrasi dengan tausiah pada saat memberikan tausyiah di bulan ramadhan dan media on line melalui media whattapps group, facebook tidak begitu masif dan website UMC.

Di era 4.0 saat ini dianggap promosi yang dilakukan masih jauh jika dibandingkan dengan Perguruan Tinggi Swasta lainnya di wilayah Cirebon. Alasan efisiensi biaya menjadi salah satu faktor kurangnya promosi penerimaan mahasiswa baru juga promosi akreditasi di Universitas Muhammadiyah Cirebon. Pemasangan baliho di tempat strategis yang sangat minim, promosi di media elektronik yang kurang masif dan promosi di media online juga sangat jarang dilakukan. 
Contohnya adalah melalui media Instagram (IG) pada gambar di bawah ini:

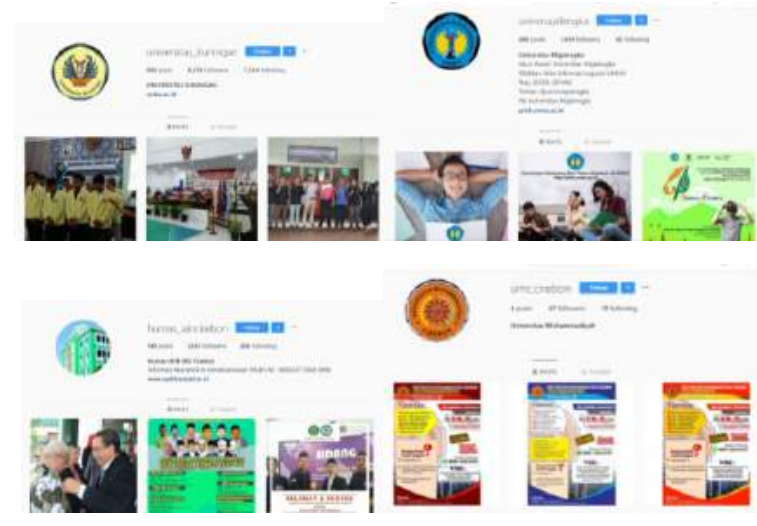

Gambar 2

Jumlah Postingan dan Follower

(Sumber : Instagram.com)

Pada gambar 2 tersebut dapat kita lihat bagaimana masifnya promosi melalui media online yang dilakukan oleh Universitas Kuningan, Universitas Majalengkan dan IAIN Cirebon. Universitas Kuningan sudah melakukan posting sebanyak 865 kali posting dan memiliki 8253 followers, Universitas Majalengkan sudah melakukan posting sebanyak 260 kali posting dan memiliki 1651 followers, IAIN Cirebon sudah melakukan 148 posting dan memiliki 1265 followers. Sedangkan Universitas Muhammadiyah Cirebon baru 4 kali posting dan hanya memiliki 67 followers.

Ini menjadi salah satu indikator kurang seriusnya Universitas Muhammadiyah Cirebon melakukan promosi melalui media online diera digitalisasi 4.0 yang sekang ini sedang menjadi tren di kalangan anak muda dan anak millenia. Harusnya ini menjadi sebuah pemikiran dan bahan diskusi yang harus segera dilakukan oleh Tim PMB agar dapat masuk melakukan media promosi melalui media online. Karena target marketing dari Tim PMB adalah para calon mahasiswa yang kebanyakan baru lulus SMA dan berusia sekitar 18-26 tahun. Dimana pada usia tersebut kecenderungan media yang digunakan dalam mencarai informasi adalah menggunakan media online.

Selain itu Tim PMB UMC juga belum begitu masif melakukan promosi menggunakan media elektronik dalam hal ini radio. Pada saat hampir sebagian Universitas Swasta di wilayah 3 Cirebon 
melakukan promosi besar besaran terkait Penerimaan Mahasiswa Baru melalui media elektronik dalam hal ini Radio. Universitas Muhammadiyah Cirebon tidak melakukannya. Ini sangat merugikan dalam mempromosikan Universitas Muhammadiyah Cirebon yang sudah memiliki akreditasi yang baik. Pemasangan baliho juga jarang sekali di temui di tempat-temat strategis. Sangat berbeda dengan Universitas swasta lainnya di wilayah 3 Cirebon yang secara masif mempromosikan perguruan tingginya.

Hasil wawancara yang dilakukan oleh peneliti kepada 75 mahasiswa dari seluruh fakultas yang ada di Universitas Muhammadiyah Cirebon menunjukkan bahwa hampir 95\% mahasiswa yang kami lakukan wawancara mengatakan bahwa mereka mendapatkan informasi PMB UMC berasal dari Keluarga, guru Bimbingan Konseling dan juga brosur. Sangat sedikit sekali yang mengetahui UMC melalui media elektronik, baliho maupun melalui media online. Ini adalah potensi yang harus terus dikembangkan oleh UMC dalam menggaet minta calon mahasiswa untuk berkuliah di Universitas Muhammadiyah Cirebon.

Perlu adanya promosi yang gencara untuk menarik calon mahasiswa agar mau bergabung di Universitas Muhammadiyah Cirebon. Bagaimana mungkin calon mahasiswa mau bergabung dalam Universitas Muhammadiyah Cirebon kalau tingkat pengetahuan calon mahasiswa baru UMC tentang UMC saja masih rendah karena kurang masifnya sosialisasi yang dilakukan UMC dalam menarik minat calon mahasiswanya untuk bergabung dan menjadi bagian dari mahasiswa UMC. Karena tahapan seseorang mau bergabung menjadi mahasiswa UMC tidak dengan membalikan telapak tangan.

Ada tahapan-tahapannya pertama adanya memberikan pengetahuan terlebih dahulu kepada calon mahasiswa tentang Universitas Muhammadiyah Cirebon baik Perguruan Tingginya maupun program studinya. Tahapan berikutnya adalah memberikan kesan yang baik kepada calon mahasiswa agar mereka memiliki sikap yang bagus terhadap UMC.

Tahap terakhir adalah meyakinkan calon mahasiswa yang sudah memiliki sikap baik terhadap UMC untuk bergabung dengan UMC. Dua tahapan awal yaitu tahap pengetahuan dan pembentukan sikap sangat membutuhkan media masaa baik itu media cetak, elektronik maupun online. Tanpa ada bantuan dari media massa sangat sulit 
sekali UMC membertikan informasi pengetahuan kepada calon mahasiswa tentang perguruan tinggi dan program studi yang ada di UMC. Begitu juga di tahap yang kedua dalam menimbulkan sikap suka terhadap UMC.

Perlu adanya dukungan dari media massa untuk menunjukkan kepada calon mahasiswa tentang keunggulankeunggulan yang dimiliki oleh UMC. Barulah tahap ketiga kita harus melakukan upaya persuasif melakukan pendekatan kepada calon mahasiswa baik melalui pameran, keluarga, guru Bimbingan Konseling agar calon mahasiswa mau bergabung dengan UMC. Tentu dalam menjalankan tahap satu dan dua yaitu pemeberian informasi dan pembentukan sikap melalui media massa membutuhkan biaya yang besar. Akan tetapi dalam promosi memang sangat penting sekali dlam pembentukan pengetahuan dan sikap calon pengguna jasa kita dalam hal ini agar mau bergabung dengan UMC.

Sedangkan untuk alasan kenapa mahasiswa mau bergabung dengan Universitas Muhammadiyah Cirebon hampir $80 \%$ mengatakan karena kampus Universitas Muhammadiyah Cirebon strategis dan dekat dengan rumah mereka. Selain itu juga dikarenakan biaya perkuliahan di Universitas Muhammadiyah Cirebon yang relatif terjangkau. Ini menjadikan keunggulan dibandingkan dengan Universitas swasta lainnya di wilayah 3 cirebon. Akan tetapi jika dilihat dari alasan yang pertama menunjukkan memang promosi yang dilakukan oleh Universitas Muhammadiyah Cirebon masih dalam lingkup daerah belum sampai nasional karena memang belum memanfaatkan media promosi yang dapat menjangkau skala nasional bahan internasional.

Tim PMB UMC belum menerapkan ciri utama dari Intregrated Marketing Communication : mempengaruhi perilaku konsumen atau pelanggan. Dalam proses mempengaruhi orang untuk melakukan perubahan perilaku agar mau bergabung dengan UMC tentu harus melalui tahap pengetahuan dan sikap terlebih dahulu. Bagaimana mungkin orang mau melakukan sesuatu dalam hal ini bergabung dengan UMC kalau pengetahuan dan sikapnya belum terbentuk secara positif. Pengetahuan disini maksudnya adalah calon mahasiswa mengetahui dengan baik tentang UMC. Sedangkan sikap dalam hal ini adalah rasa suka terhadap UMC. 
Tahapan pengetahuan dan sikap ini harusnya disampaikan oleh Tim PMB melalui media massa agar dapat menjangkau semua lapisan masyarakat. Media massa bisa berupa cetak yaitu melalui baliho, surat kabar ataupun brosur. Media elektronik melalui radio dan televisi ataupun media online melalui website ataupun media sosial; (2) berawal dari pelanggan dan calon pelanggan.

Berdasarkan hasil wawancara dengan mahasiswa dari segi fasilitas UMC sudah masuk katagori bagus. Pembenahan yang perlu diperbaiki adalah pada segi konektivitas internet di lingkungan kampus; (3) melakukan satu atau segala cara dalam melakukan kontak dengan pelanggan atau calon pelanggan. Tim PMB belum maksimal dalam melakukan kontak dengan berbagai macam alat komunikasi kepada calon pelanggannya. Terutama dengan menggunakan media online. Padahal apabila Tim PMB menggunakan media online dalam melakukan kontak terutama media sosial, maka jalinan komunikasi antara UMC dengan calon mahasiswa dapat berlangsung dengan maksimal; (4) berusaha menciptakan sebuah sinergi; (5) menjalin hubungan yang baik antara organisasi atau perusahaan dengan pelanggannya. Hal ini juga belum dilakukan upaya secara maksimal.

\section{PEMBAHASAN}

Analisis yang digunakan oleh peneliti adalah analisis SWOT yaitu peralatan analisis untuk mengetahui kekuatan yang dimiliki UMC, Kelemahan dari UMC, Peluang dan juga Ancamannya. Berdasarkan hasil pengumpulan data melalui wawancara mendalam dengan ketua Penerimaaan Mahasiswa Baru dan juga dari para mahasiswa di lingkungan UMC dari berbagai Fakultas dan referensi beberapa literatur diperoleh hasil sebagai berikut:

a. Strengths (Kekuatan)

Kekuatan dari Universitas Muhammadiyah Cirebon sangat banyak sekali. Adapun Kekuatan yang dimaksud sebagai berikut:

1. Ekuitas merek dari UMC sudah sangat baik karena berada di bawah naungan Organisasi Islam yang sangat besar di Indonesia yaitu "Muhammadiyah". Hampir semua masyarakat Indonesia pada umumnya ataupun masyarakat Cirebon pada khususnya sudah paham betul dengan Organisasi Islam Muhammadiyah.

2. Akreditasi Perguruan Tinggi yang sudah mendapatkan nilai "B" dan sebagian besar program 
studinya juga sudah terakreditasi "B".

3. Fasilitas perkuliahan yang cukup megah di tunjang letak UMC yang sangat strategis.

4. Biaya perkuliahan yang kompetitif dibandingankan universitas lain dan mudah terjangkau untuk kalangan menengah ke bawah.

5. Tersedianya berbagai macam beasiswa baik dari internal, swasta maupun dari pemerintah.

6. Sumber daya manusia yang bagus dan memenuhi syarat baikmdari segi Dosen maupun Tenaga Kependidikan.

b. Weakness (Kelemahan)

Sedangkan kelemahan dari UMC antara lain :

1. Kurangnya media promosi yang digunakan oleh pihak UMC dalam mempromosikan diri UMC baik melalui media cetak, elektronik dan online. Sehingga mahasiswa UMC sebagian besar masih di wilayah 3 Cirebon, Majalengka, Indramayu dan Kuningan.

2. Masih adanya anggapan bahwa melakukan promosi hanya akan menghabiskan biaya saja. Padahal melakukan promosi adalah bagian dari investasi.

c. Opportunities (Peluang)

Dengan banyaknya kekuatan yang dimiliki oleh UMC bisa membuat peluang yang dimiliki oleh UMC juga cukup besar antara lain:

1. Organisasi yang bergerak di bidang pendidikan memiliki prospek bertahan yang cukup baik. Karena pendidikan adalah kebutuhan pokok di masyarakat.

2. Adanya nama organisasi Muhammadiyah sebagai induk dari UMC membuat orang akan lebih mempercayakan putra putrinya untuk di kuliahkan ke tempat tersebut.

3. Mendapatkannya nilai $\mathrm{B}$ dalam akreditasi perguruan tinggi membuat kepercayaan meningkat dari masyarakat.

d. Threats (Ancaman)

Sedangkan ancaman yang dimiliki oleh UMC adalah :

1. Banyaknya Perguruan Tinggi swasta dan negeri di wilayah 3 membuat masyarakat memiliki banyak pilihan untuk menentukan tempat memperoleh pendidikan. Apalagi saat ini hampir sebagian besar akreditasi perguruan tinggi di wilayah 3 sudah memperoleh nilai yang sama dengan UMC yaitu "B"

2. Adanya perguruan tinggi negeri di wilayah 3 juga menjadikan ancaman jika tidak ada pembatasan penerimaan mahasiswa baru di Perguruan 
Tinggi Negeri. Apalagi tahun ini sudah ada ITB cabang Cirebon.

Dari hasil analisis SWOT di atas dapat diketahui bahwa kekuatan UMC sangat banyak sekali begitu juga peluang yang dimilikinya. Sedangkan dari segi ancaman sangat minimal sekali bagi UMC. Yang memerlukan perhatian dari analasis tersebut terletak pada aspek kelemahannya yaitu kurang gencarnya atau masifnya UMC dalam mempromosikan diri sebagai Universitas yang memiliki fasilitas maksimal dan juga akreditasi perguruan tinggi " $\mathrm{B}$ ".

Media promosi yang digunakan belum tersentuh secara menyeluruh mulai dari media cetak yaitu baliho yang minim terpasan di wilayah 3 begitu juga promosi melalui media koran. Selanjutnya di media elektronik tidak ada kerjasama dalam mempromosikan diri mengenai UMC melalui radio. Begitu juga media online. UMC hanya mengandalkan media sosial facebook saja. Itupun sebagian besar berisi kegiatan yang kurang boombastis. UMC belum menyentuh media sosial twitter maupun media sosial Instagram. Padahal target marketing UMC adalah para kaum muda yang sangat dekat dengan media online dn media sosial. Segala informasi dari calon mahasiswa mereka peroleh melalui smartphone yang mereka miliki.

\section{SIMPULAN}

Dari hasil penelitian yang dilakukan dapat diambil sebuah kesimpulan bahwa saat ini Universitas Muhammadiyah Cirebon tidak melakukan promosi secara maksimal terutama dalam proses Penerimaan Mahasiswa Baru. UMC masih mengandalkan kegiatan promosi melalui pendekatan Guru Bimbingan Konseling.

Media promosi menggunakan media massa tidak dilakukan secara maksimal baik dari media cetak dalam hal ini baliho dan surat kabar, media elektronik melalui radio dan televisi lokal, maupun media on line yaitu melalui media sosial twitter dan instagram.

Pihak UMC masih menganggap bahwa melakukan promosi sebagai kegiatan yang menghabiskan banyak anggaran. Pihak UMC tidak menganggap bahwa promosi adalah bagian dari investasi jangka panjang.

\section{DAFTAR PUSTAKA}

Arikunto, Suharsimi. 2010. Prosedur Penelitian Suatu Pendekatan Praktik. Jakarta: PT Rineka Cipta 
Cangara, Hafied. 2013. Perencanaan dan Strategi Komunikasi. PT. Raja Grafindo Persada. Jakarta

Creswell, John W. 2010. Research Desaign Pendekatan Kualitatif, Kuantitatif dan Mixed. Yogyakarta: Pustaka Pelajar

Kriyantono, Rachmat. 2014. Teknik Praktis Riset Komunikasi. Jakarta: Kencana

Morissan. 2014. Periklanan: Komunikasi Pemasaran Terpadu. Jakarta: Kencana

Shimp, Terence A. 2003. Periklanan Promosi. Jakarta: Erlangga 